\title{
Article \\ ESR1 ChIP-Seq Identifies Distinct Ligand-Free ESR1 Genomic Binding Sites in Human Hepatocytes and Liver Tissue
}

\author{
Joseph M. Collins ${ }^{1}$, Zhiguang Huo ${ }^{2}$ and Danxin Wang ${ }^{1, *(\mathbb{D}}$ \\ 1 Center for Pharmacogenomics, Department of Pharmacotherapy and Translational Research, \\ College of Pharmacy, University of Florida, Gainesville, FL 32610, USA; jcoll86@ufl.edu \\ 2 Department of Biostatistics, College of Public Health \& Health Professions, University of Florida, \\ Gainesville, FL 32610, USA; zhuo@ufl.edu \\ * Correspondence: danxin.wang@cop.ufl.edu; Tel.: +1-352-273-7673; Fax: +1-352-273-6121
}

Citation: Collins, J.M.; Huo, Z.; Wang, D. ESR1 ChIP-Seq Identifies Distinct Ligand-Free ESR1 Genomic Binding Sites in Human Hepatocytes and Liver Tissue. Int. J. Mol. Sci. 2021, 22, 1461. https://doi.org/10.3390/ ijms22031461

Academic Editor: Farzad Pakdel Received: 17 December 2020

Accepted: 29 January 2021

Published: 2 February 2021

Publisher's Note: MDPI stays neutral with regard to jurisdictional claims in published maps and institutional affiliations.

Copyright: (c) 2021 by the authors. Licensee MDPI, Basel, Switzerland. This article is an open access article distributed under the terms and conditions of the Creative Commons Attribution (CC BY) license (https:// creativecommons.org/licenses/by/ $4.0 /)$.

\begin{abstract}
The estrogen receptor alpha (ESR1) is an important gene transcriptional regulator, known to mediate the effects of estrogen. Canonically, ESR1 is activated by its ligand estrogen. However, the role of unliganded ESR1 in transcriptional regulation has been gaining attention. We have recently shown that ligand-free ESR1 is a key regulator of several cytochrome P450 (CYP) genes in the liver, however ligand-free ESR1 has not been characterized genome-wide in the human liver. To address this, ESR1 ChIP-Seq was conducted in human liver samples and in hepatocytes with or without 17beta-estradiol (E2) treatment. We identified both ligand-dependent and ligandindependent binding sites throughout the genome. These two ESR1 binding categories showed different genomic localization, pathway enrichment, and cofactor colocalization, indicating different ESR1 regulatory function depending on ligand availability. By analyzing existing ESR1 data from additional human cell lines, we uncovered a potential ligand-independent ESR1 activity, namely its co-enrichment with the zinc finger protein 143 (ZNF143). Furthermore, we identified ESR1 binding sites near many gene loci related to drug therapy, including the CYPs. Overall, this study shows distinct ligand-free and ligand-bound ESR1 chromatin binding profiles in the liver and suggests the potential broad influence of ESR1 in drug metabolism and drug therapy.
\end{abstract}

Keywords: estrogen receptor alpha; ESR1; ChIP-Seq; genomic binding; cytochrome p450s

\section{Background}

The estrogen receptor alpha $(\mathrm{ER} \alpha, \mathrm{ESR} 1)$ is one of the best characterized nuclear receptors due to its extensive roles regulating physiology, pathophysiology, and development of diverse tissues (see reviews by [1-3]), in particular its role in breast cancer progression [4]. Besides reproductive tissues, ESR1 is known to have an important role in the liver, regulating lipid and glucose metabolism [5,6]. Altered ESR1 expression is associated with development of hepatocellular carcinomas $[7,8]$, and is related to the sexually dimorphic nature of several liver diseases, for example, hepatocellular carcinomas [9], nonalcoholic fatty liver disease $[6,10,11]$, and liver gene expression [12] including the cytochrome P450 (CYP) drug metabolizing enzyme CYP3A4 [13].

Like the other nuclear receptors, ESR1 canonically functions as a ligand-dependent transcription factor (TF) where association with estrogen promotes ESR1 binding to the estrogen response element (ERE) and thereby enables regulation of target genes. However, binding of ESR1 to DNA in the absence of estrogen has been shown at specific promoters in osteoblasts [14] and MCF-7 breast cancer cells [15]. By depleting ESR1 in MCF- 7 cells, Caizzi et al. showed that ligand-free ESR1 binds to several thousand locations throughout the genome and regulates the expression of hundreds of genes, indicating that ESR1 maintains regulatory function in the absence of estrogen [16]. More recently, a study thoroughly categorized ESR1 binding in MCF-7 cells, identifying distinct binding sites both 
before and after E2 treatment, further supporting estrogen-mediated and ligand-free ESR1 binding sites throughout the genome [17].

Recently, we identified ligand-free ESR1 as a master regulator for the expression of several cytochrome P450s (CYPs) including CYP3A4 [18]. CYP3A4 is the most abundant drug metabolizing enzyme in human liver and is responsible for metabolism of numerous drugs [19]. Up- or down-regulation of ESR1 in hepatocytes or the hepatic-derived cell line Huh7 changed the expression of multiple CYP enzymes [18], implicating the broad influence of ESR1 on the metabolism of xenobiotics. While estrogen-induced expression of several CYP enzymes (e.g., CYP2A6/CYP1A1) $[20,21]$ is known, mechanisms underlying ligand-free ESR1 regulation in the liver remain uncertain.

To better understand the role of ESR1 in the liver, we conducted ESR1 Chromatin Immunoprecipitation followed by high throughput sequencing (ChIP-Seq) in human liver samples and in primary culture hepatocytes with or without 17-beta-estradiol (E2) treatment. Consistent with results in MCF-7 cells [16,17], we found distinct chromatin binding sites of ligand-bound and ligand-free ESR1. Our results indicate that ESR1 regulates key processes in the liver via ligand-dependent and ligand-independent roles. To our knowledge, this is the first ESR1 ChIP-Seq study conducted in human liver tissues and in hepatocytes.

\section{Results}

\subsection{ESR1 Genomic Localization in Hepatocytes and the Liver Tissues}

We detail ESR1 binding in the liver genome-wide using ChIP-Seq. Six liver biopsy samples were combined (three males and three females, see Supplemental Table S1 for demographic information of donors) and chromatin immunoprecipitation was conducted against ESR1 and compared to an input DNA control. To investigate ESR1 chromatin localization changes in response to estrogen treatment, ESR1 ChIP-Seq was also conducted in primary culture hepatocytes grown in media lacking estrogen and treated with DMSO (untreated) or treated with E2 (E2-treated). Analysis of ESR1 enrichment in these samples identified ESR1 binding sites throughout the genome (number of peaks, liver $n=14,664$, E2-treated $n=5587$ and untreated $n=9510$ ) (Figure 1A). Example ChIP-Seq peaks are shown in Supplemental Figure S1. Peaks were then assessed for any sequence overlap between samples, revealing 1720 shared ESR1 binding sites among all three samples. These 1720 peaks contributed to $18 \%, 31 \%$, and $12 \%$ of peaks identified in untreated, E2- treated, and liver data sets, respectively.

Differential binding of ESR 1 in response to E2 treatment was determined by comparing the E2-treated and untreated samples. ESR1 binding was then categorized into three groups. ESR1 binding sites identified in E2-treated hepatocytes that were at least four times higher than in untreated hepatocytes were labeled as "gained with treatment" $(n=1551)$. Conversely, peaks identified in untreated hepatocytes compared to E2-treated hepatocytes were considered "lost after treatment" $(n=2825)$. Finally, peaks that were found in both treated and untreated samples (i.e., peaks that are not different by 4 -fold between these two conditions) were categorized as "E2-independent" ( $n=2473)$ (Figure 1B). The 1720 peaks that were shared with the liver sample contributed to $69 \%(1720 / 2473)$ of the peaks identified in the E2-independent data set. These results indicated that in hepatocytes, ESR1 localization occurs through both ligand-dependent (lost and gained) and ligandindependent mechanisms.

Next, we evaluated the genomic distribution of ESR1 in response to estrogen and in the liver tissues. We first utilized genome annotation and the UCSC Genome Browser [22] to spatially assign peaks relative to transcription start sites (TSS's), exons, and introns (Figure 2A). In the lost and gained data sets, approximately 15\% of ESR1 binding occurred within promoters $( \pm 500 \mathrm{bp})$. In the E2-independent and liver datasets, binding in promoter regions was roughly double (30\%) the amount in the E2-responsive datasets. Comparison of ESR1 spatial localization between the datasets found that the E2-independent peaks show significantly different distribution compared to the lost $\left(p=0.019, \chi^{2}\right.$ test) and gained 
( $p=0.021, \chi^{2}$ test) categories, but that E2-independent is not different from the liver sample. All four datasets had comparable enrichment upstream and downstream of genic regions. However, within gene transcribed regions, the E2-dependent datasets aligned primarily within introns (32\% and 37\% in gained and lost, respectively), whereas E2-independent binding and ESR1 binding in the liver was more evenly distributed across both exons and introns.
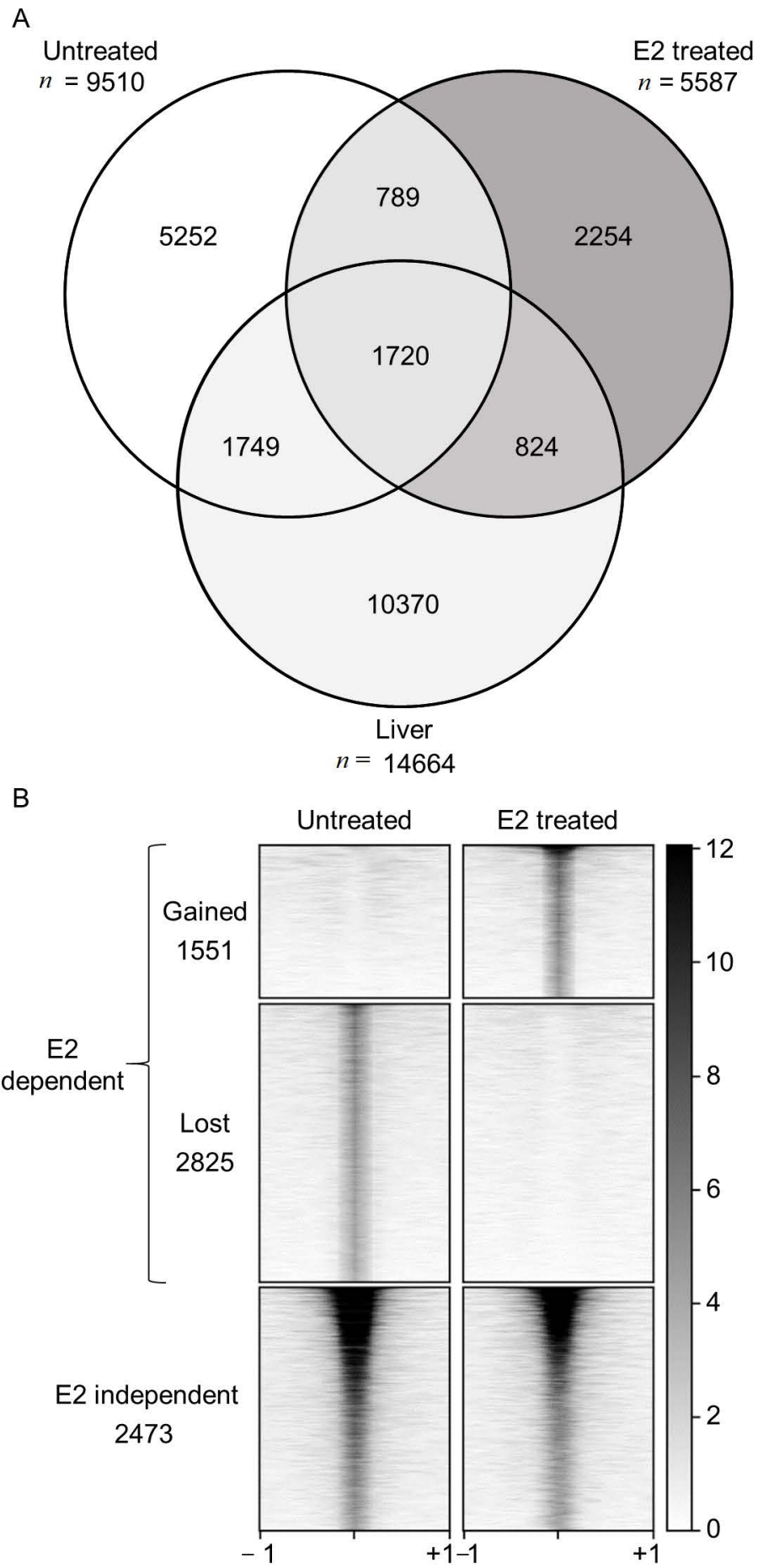

Figure 1. ESR1 ChIP-Seq peaks identified and classification of ESR1 binding in response to E2 treatment. (A) Venn diagram detailing peak overlap in each sample. (B) ChIP-seq read density heatmap showing ESR1 enrichment in each binding category. Density plots are centered on ESR1 peaks within $\mathrm{a} \pm 1 \mathrm{~kb}$ window. Darker coloration indicates higher ChIP-Seq read counts. 


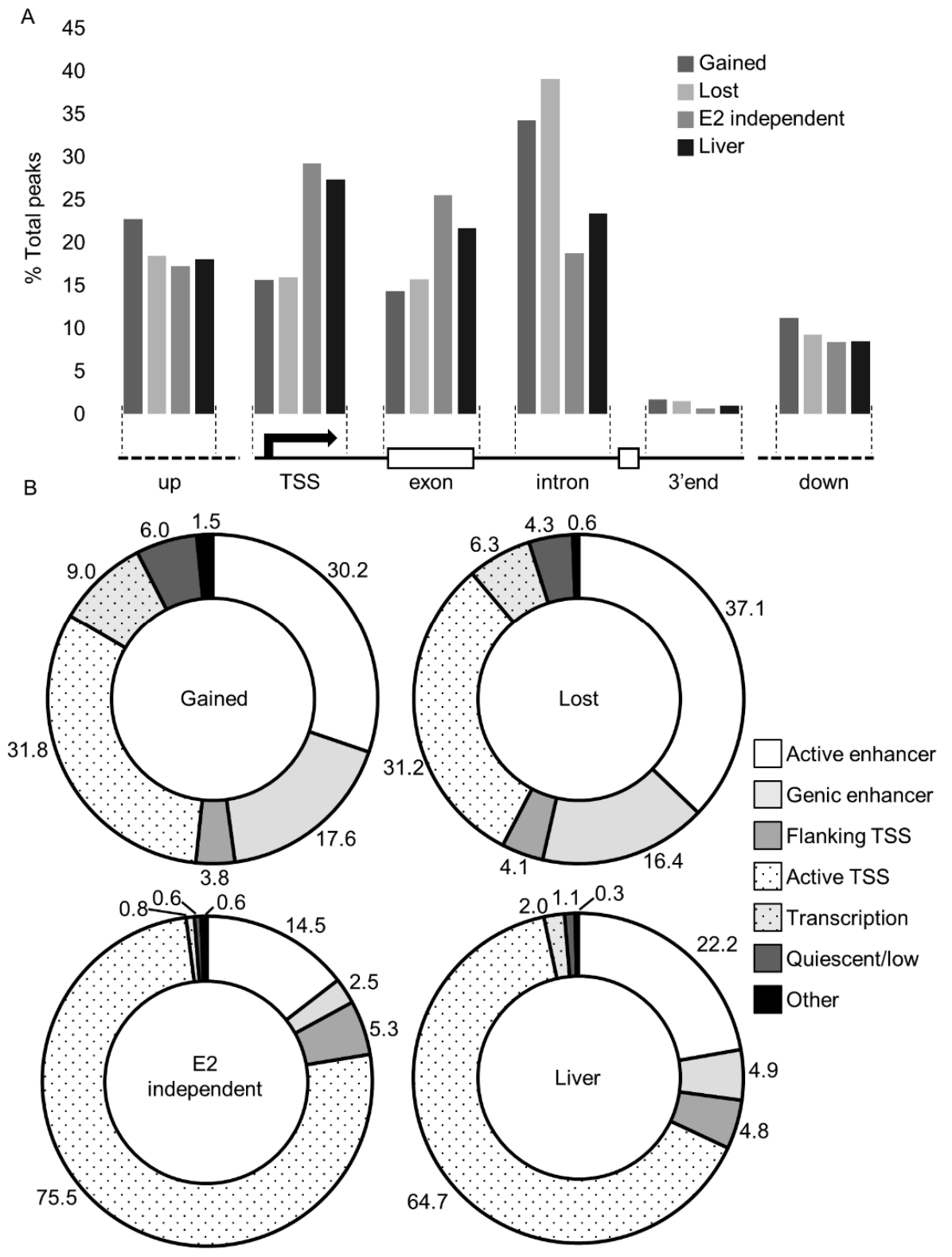

Figure 2. Genomic localization of ESR1. (A) Spatial localization determined by comparison of peaks to gene annotation in the UCSC genome browser. Values are percentages of total peaks in each region from each sample. Location is depicted in the cartoon below the graph, in the following order (left to right): upstream ( -500 to $-10 \mathrm{~kb}$ of TSS, up), proximal promoter ( $\pm 2 \mathrm{~kb}$ of transcription start site, TSS), exonic, intronic, $3^{\prime}$-end ( $\pm 500 \mathrm{bp}$ from transcription end site), and downstream (+500 to $+10 \mathrm{~kb}$ of TES, down). (B) Localization as determined by epigenetic histone marks. Values are percentages of total peaks. ChromHMM [23] was trained with data from liver samples and used to categorize the ESR1 peaks. TSS, transcription start site.

Studies in MCF-7 cells have illustrated that ESR1 binding primarily associates with enhancers [17]. To infer the genomic landscape of ESR1 binding, we utilized the ChromHMM algorithm [23] trained with ChIP-seq data on histone marks conducted in liver tissue and then compared our peak lists with the resulting ChromHMM model (Figure 2B). Liganddependent peaks were primarily associated with enhancers $(47.8 \%$ and $53.5 \%$, in gained and lost, respectively). In contrast, peaks associated with ligand-independent binding and those in liver tissues were more commonly located near TSSs $(75.5 \%$ and $64.7 \%$, respectively). These results largely agree with the spatial proximity-based approach (Figure 2A) and indicate distinct binding profiles for ligand-dependent and ligand-independent ESR1. 


\subsection{ESR1 Peaks Colocalize with a Variety of Trans-Factors}

Previous publications have shown that in addition to binding the canonical ERE, ESR1 is commonly associated with the motifs of other TFs. For example, ESR1 peaks in MCF-7 cells also contain motifs for forkhead box protein A1 (FOXA1) and activating enhancer binding protein 2 gamma (AP2 $\gamma$ ) [16,17], indicating the involvement of other TFs in ESR1-DNA binding. Analysis of motifs enriched in the ligand-dependent, independent, and liver samples revealed enrichment of several different co-factor motifs (Figure 3A). Peaks that were lost after treatment contained motifs associated with a variety of TFs: fos-related antigen-1 (FRA1), nuclear factor I C (NFIC), CCAAT/enhancer-binding protein beta (CEBPB), interferon regulatory factor 2 (IRF2), and hepatocyte nuclear factor 4 alpha (HNF4A). Gained sites primarily contained the ERE, in agreement with the canonical ligand-induced localization of ESR1 [16,17]. Gained peaks also contained several lessenriched motifs including the retinoid $X$ receptor alpha (RXRA), activator protein 1 (AP-1), RAR related orphan receptor A (RORA), and MYC associated zinc finger protein (MAZ). It is worth noting that both the RXRA and RORA motifs are ERE "half-sites", which have been identified in previous ESR1 ChIP-Seq experiments [16,17]. In the ligand-independent peaks, the general factor Y (GFY) element and zinc finger protein 143 (ZNF143) were both highly enriched, followed by the forkhead box L1 (FOXL1), ETS-domain protein 1 (ELK1), and the GC-box. In the liver sample, the most enriched motif was the GFY-Staf motif, which at its core contains the GFY motif also found in the E2-independent peaks. The liver peaks also contained motifs recognized by the nuclear transcription factor Y (NFY), RXRA, ELK4, and JUN:FOS. Overall, these results suggest that ESR1 functions in the liver similarly to MCF-7 cells [17], binding the ERE in the presence of estrogen and also associating with other motifs, possibly indirectly via cofactors. Gained

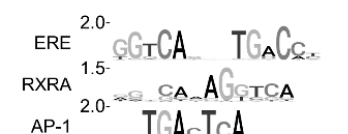
RORA ${ }_{2.0}{ }^{1 .}$ ACAAGGTCACAE

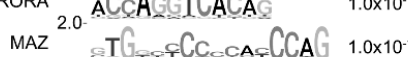
${ }_{\text {FRA }}{ }^{1.5}$ TSA TSA. NFIC 20. - EXCCCAA ${ }_{\text {IRF2 }}{ }_{2.0}$. AACTTT ATTTT $_{\text {S. }}$ СЕврв $2 .{ }^{\circ}$.T $A A$ HNFAA ${ }^{100}$ IGGACTTTGGCC p-value B
$1.0 \times 10^{-167}$
$1.0 \times 10^{-32}$
$1.0 \times 10^{-28}$
$1.0 \times 10^{-16}$
$1.0 \times 10^{-15}$ $1.0 \times 10^{-46}$ $1.0 \times 10^{-41}$ $1.0 \times 10^{-30}$ $1.0 \times 10^{-23}$ $1.0 \times 10^{-21}$ $\mathrm{GFY}_{1.5}^{2.0-}$ T..TGGG $\quad$ TGTAGT $1.0 \times 10^{-882}$ ZNF143 ${ }^{1.5}$ CESGCATCTGGGA $1.0 \times 10^{-487}$

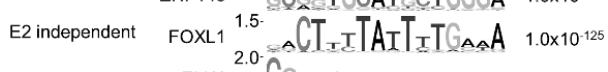
ELK1 ${ }^{2.0} \mathrm{C}$ AA. 우 $1.0 \times 10^{-79}$

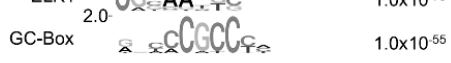

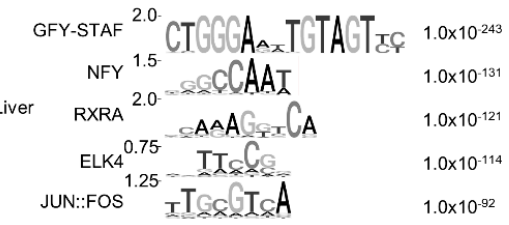
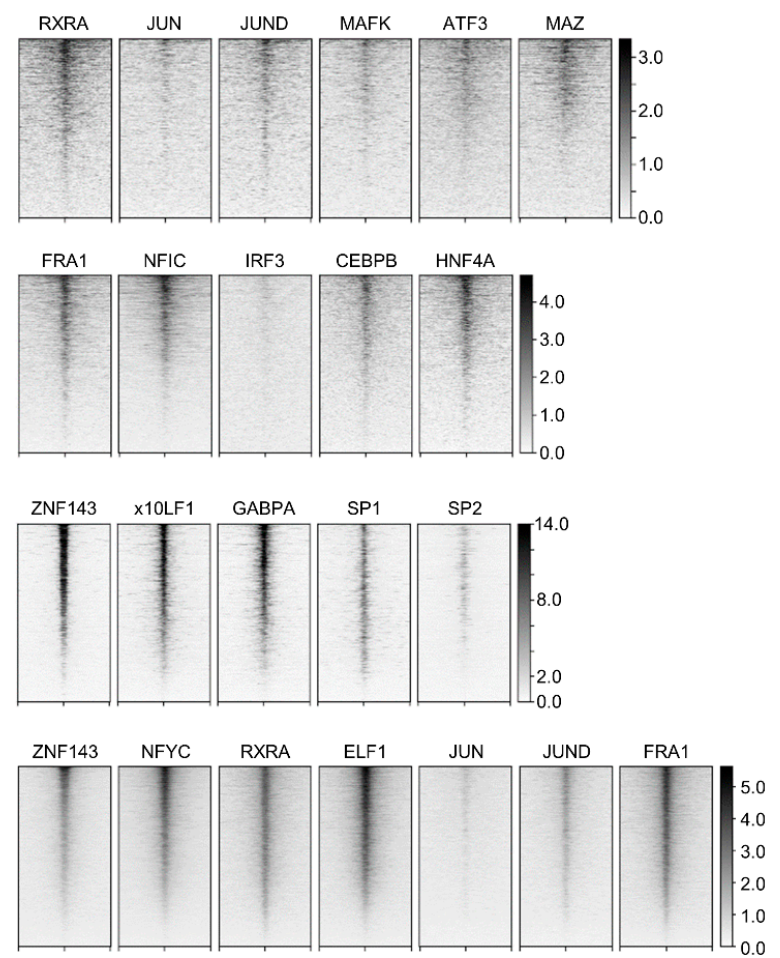

Figure 3. Motif enrichment and colocalization of transcription factors with ESR1 peaks. (A) The top five motifs in each sample are shown. The top bit value score is indicated to the left of each motif diagram. The p-value indicates enrichment of the motif compared to background. (B) Heatmaps showing ChIP-Seq read density centered on ESR1 peaks within a $\pm 5 \mathrm{~kb}$ window. TF ChIP-Seq data were obtained from published datasets conducted in HepG2 cells. Darker intensity indicates higher enrichment, as indicated by the legends to the right of the plots. 
To determine whether the motifs enriched in the ESR1 peaks were bona fide binding sites in liver cells, published ChIP-Seq datasets with different TFs in HepG2 cells [24,25] were analyzed. Overall, we observed concomitant occurrence of these TFs with their corresponding motifs in the ESR1 peaks, supporting colocalization of these TFs with ESR1 (Figure 3B). In some cases, due to unavailability of ChIP-Seq data with a particular TF, similar TFs were chosen to act as surrogates for the enriched motifs. For instance, AP-1 is a complex of proteins that can potentially contain the JUN, FOS, MAF, and/or ATF proteins [26]. In the gained sample, JUN, JUND, MAFK, and ATF3 showed varying degrees of co-enrichment with the ESR1 peaks, possibly reflecting ESR1 preference for the different AP-1 complex constituents. In general, compared to the other ESR1 categories (lost, independent, and liver), the gained peaks showed more diffuse and less centralized TF colocalization, likely because ESR1 is directly binding to the ERE.

In the lost peaks, four TFs (FRA1, NFIC, CEBPB, and HNF4A) associated with the top five motifs all showed high enrichment at the ESR1 peak center (Figure 3B). IRF3 was chosen as a substitute for IRF2, as there was no HepG2 IRF2 dataset available and the IRF family of proteins all recognize a similar DNA motif [27]. However, there was little enrichment of IRF3 at the lost peaks, which may be due to IRF2 and IRF3 having different regulatory targets [28], thereby making IRF3 a poor alternative for visualizing IRF2 localization.

For the liver and ligand-independent samples, analysis of a factor binding the top GFY and GFY-Staf motifs in each sample was not feasible, as there is no definitive factor that binds this motif [29]. Still, ZNF143 showed high co-enrichment in the peak center of the ligand-independent peaks. No ELK1 dataset was available, so ELF1 and GABPA were chosen as substitutes due to their high motif similarity and SP1 and SP2 were chosen for the GC-Box as they are well-characterized GC-Box binding proteins [30]. ELF1, GABPA, and SP1 all showed high centralized colocalization with the ligand-independent ESR1 peaks.

The liver sample showed high centralized enrichment with NFYC, RXRA, ELF1 (ELK4), and JUND, JUN, and FRA1 (JUN::FOS). While conducting these colocalization analyses, it became more apparent how similar the collection of motifs in the liver was compared to those found in the three ESR1 binding conditions in hepatocytes. Like the gained peaks, the liver sample showed higher enrichment of JUND than of JUN and strong enrichment of RXRA. FRA1 selected as an ancillary JUN::FOS protein, showed strong central colocalization, and was also the top motif identified in the lost peaks. Finally, the liver sample also showed dense ELF1 and ZNF143 enrichment like the E2-independent sample. Although ZNF143 was not an identified motif in the liver sample per se, it was visualized due its partial motif overlap with GFY-Staf (the top identified motif in the liver). Overall, it appears that in the liver, ESR1 colocalizes with a variety of factors observed in both the ligand-dependent and independent datasets, reflecting a more varied localization possibly due to varying estrogen levels occurring in the combined liver sample.

It is noted that many of the co-enriched TFs show overlap with the various conditions despite not being in the top 5 motifs identified for that specific condition (Supplemental Figure S2). Many of these TF motifs are highly similar and/or are at a higher p-value in other ESR1 binding conditions. Overall, the results support indirect ESR1 binding (i.e., not through direct ERE interaction) at hepatic/liver chromatin through interaction with multiple proteins.

To validate ESR1 and ZNF143 localization in liver cells, we conducted ChIP-qPCR and tested for both ESR1 and ZNF143 enrichment at three genomic locations in the E2Independent dataset containing ZNF143 motifs (Figure 4). We confirmed ESR1 enrichment (3- to 8-fold) at these sites. Moreover, as expected, we also observed strong ZNF143 enrichment (4- to 13-fold) at each site. These results support colocalization of ZNF143 at ESR1 ChIP-Seq peaks in the absence of E2. Whether ESR1 binds to ZNF143 motifs directly or indirectly through interaction with ZNF143 or other factors requires further investigation. 


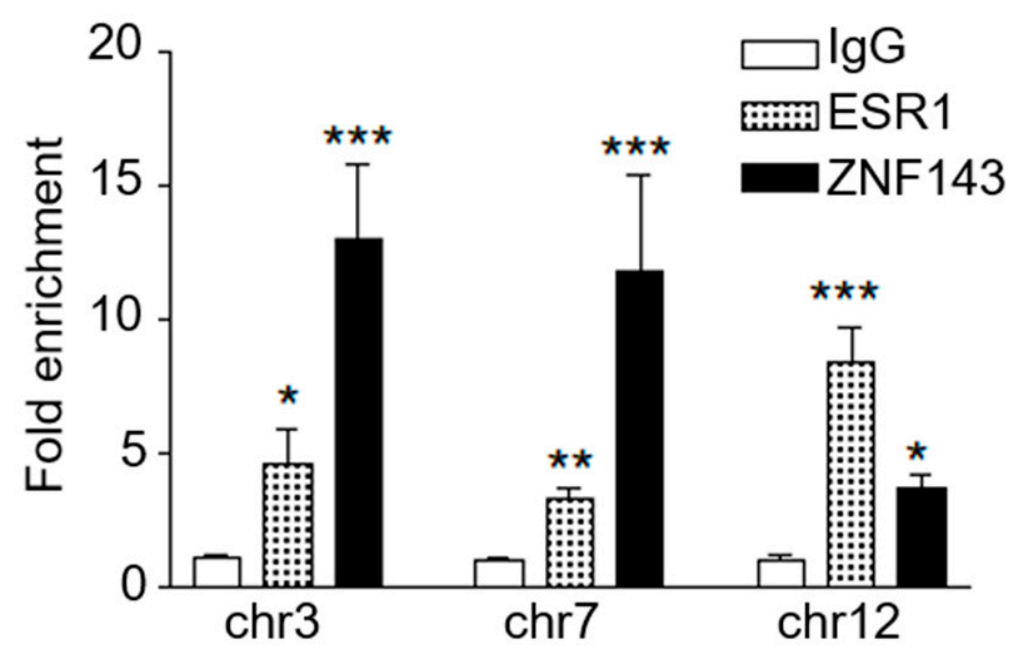

Figure 4. ChIP-qPCR confirmed enrichment of ESR1 and ZNF143 at three genomic sites identified in the E2-Independent sample. Data is shown as fold enrichment over the IgG control. Asterisks indicate statistically significant difference between ESR1/ZNF143 and the IgG control (ANOVA with Bonferroni post-test, ${ }^{*} p<0.05 ;{ }^{* *} p<0.01$; ${ }^{* * *} p<0.001$ ). See Supplemental Table S5 for information about the three chromatin targets.

\subsection{Comparison to Other Cell Types}

The results from the motif enrichment and TF co-localization analyses suggested that ESR1 association with some factors in the liver is determined by the ligand (e.g., FRA1 only exists prior to treatment) while others exist regardless of E2 treatment (e.g., ZNF143). To determine whether these dynamic and static TF-TF interactions were unique to the liver, we analyzed six additional cell line ESR1 ChIP-Seq datasets: endometrial cancer (ECC1) [24], endometrial adenocarcinoma (Ishikawa) [31], prostate cancer (VCaP) [32], osteosarcoma (U2OS) [33], ovarian cancer (SKOV3) [34], and breast cancer (MCF-7) [35]. ESR1 peaks from these samples were similarly separated into gained, lost, and E2-independent categories (Supplemental Table S2). Motif enrichment analyses were conducted on each group and the top five motifs from each category were compared to the motifs we observed in hepatocytes (Figure 5). To compare motifs, we used the universal motif package [36] which provides a p-value reflecting the similarity of two or more motif matrices. In the gained peaks, as expected, the predominately enriched motif in all cell types was the ERE. When comparing the lost peaks, there was little motif similarity which suggests that prior to ligand binding, ligand-dependent ESR1 chromatin occupancy is determined by different cofactors in different cell lines, which may contribute to cell-specific gene regulation by ESR1. Interestingly, in the ligand-independent peaks, we found that the GFY motif was the most enriched motif in ECC1, SKOV3, and Ishikawa cell lines, identical to what we observed in hepatocytes (Figure 5). Furthermore, the independent peaks in the three cell lines were also enriched for the ZNF143 motif, and the ECC1 and Ishikawa cell lines also contained the Foxl1 motif. These results support a common underlying mechanism promoting ligand-independent localization of ESR1 to chromatin. 


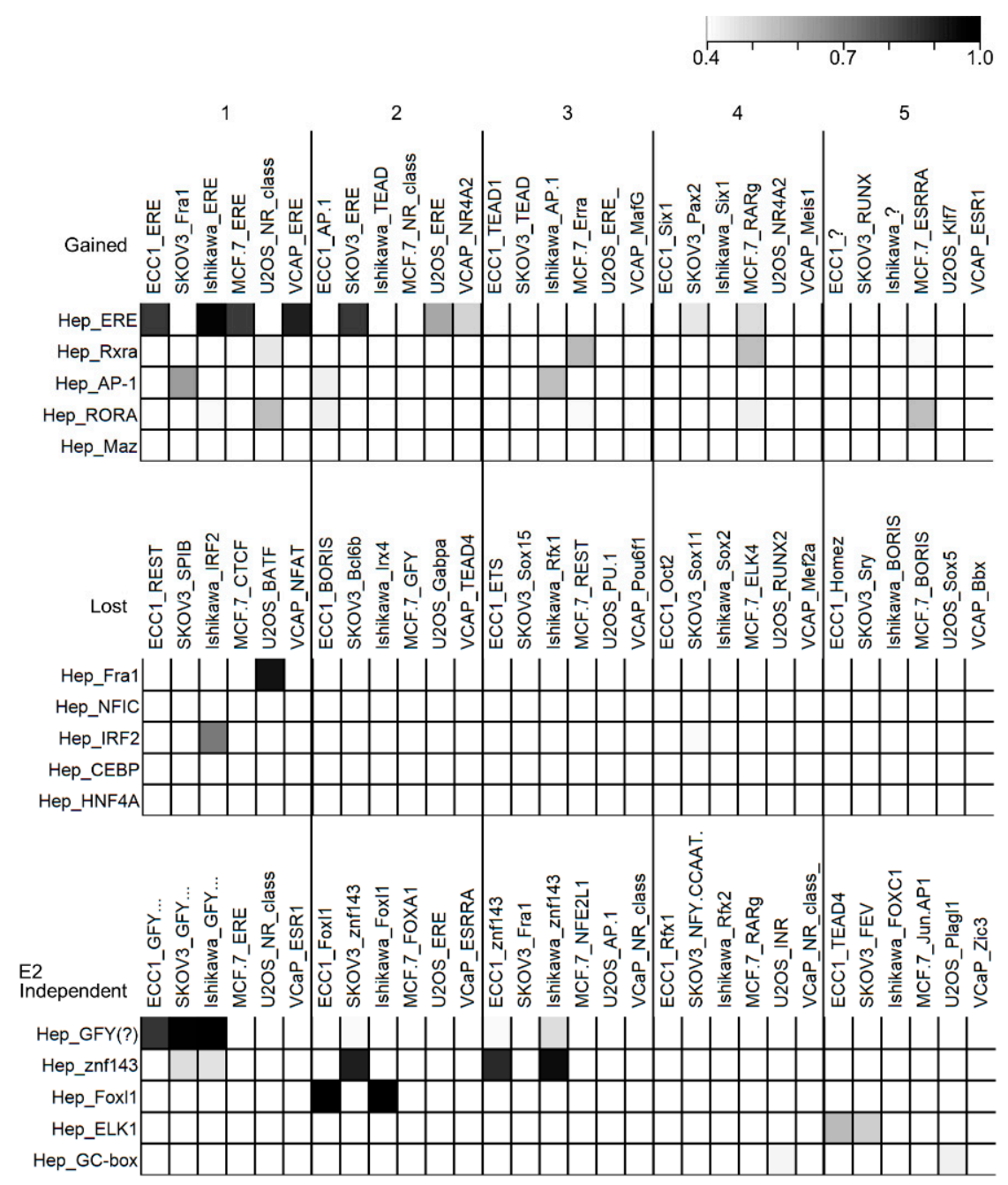

Figure 5. Comparison of enriched motifs identified for ligand-responsive and ligand-independent ESR1 peaks in various cell lines. Rows and columns are named with the cell type followed by the motif name (unknown motifs are labeled as "?"). Comparison matrices are separated by the ESR1 binding category (Gained, Lost, and E2 independent). Within each matrix, motifs from each cell line are compared to the top five motifs identified in the liver cells (row names, left). Each group is further divided into descending subgroups (left to right), with subgroup 1 being the \#1 most enriched motif for the other six cell lines (column names) and subgroup five is the fifth most enriched motif (indicated by the numbers at the top of the figure). Darker cells indicate more similar motifs, ranging from identical (1) to not similar (0.4 or less), shown at the top right of the figure. Hep, hepatocytes.

\subsection{Pathways Associated with ESR1 Genomic Localization}

To determine the pathways regulated by ESR1 in the liver, gene ontology (GO) analysis of the datasets was conducted (Table 1). GO-terms in the estrogen-dependent peak datasets were enriched in liver-related processes: with gained pathways including response to insulin, alcohol metabolism, and lipoprotein activity while lost pathways were associated with bile acid metabolism and glucose transport. In the ligand-independent dataset, pathways were related to ncRNA metabolism and protein synthesis. Pathways in the liver sample were most like those found in the ligand-independent group and included mRNA turnover and protein synthesis. These results suggest that ESR1 may play two broad roles in the liver: one where dynamic localization in response to E2 functions to regulate key liver-specific processes and another ligand-independent role that controls more general cellular activities. 
Table 1. GREAT analysis of ESR1 ChIP-Seq peaks, top five terms are shown.

\begin{tabular}{cccc}
\hline Sample & Description & BinomFdrQ & GO Term \\
\hline Gained & cellular response to insulin stimulus & $4.47 \times 10^{-6}$ & GO:0032869 \\
& alcohol metabolic process & $7.15 \times 10^{-6}$ & GO:0006066 \\
& cell junction assembly & $6.21 \times 10^{-4}$ & GO:0034329 \\
& regulation of lipoprotein lipase activity & $3.14 \times 10^{-3}$ & GO:0051004 \\
Lost & multicellular organism growth & $1.32 \times 10^{-2}$ & GO:0035264 \\
& regulation of intrinsic apoptotic signaling pathway & $4.36 \times 10^{-5}$ & GO:2001242 \\
& bile acid metabolic process & $7.14 \times 10^{-5}$ & GO:0008206 \\
& glucose transport & $2.62 \times 10^{-4}$ & GO:0015758 \\
Independent & embryonic retina morphogenesis in camera-type eye & $7.28 \times 10^{-3}$ & GO:0060059 \\
& reactive nitrogen species metabolic process & $1.59 \times 10^{-2}$ & GO:2001057 \\
& ncRNA metabolic process & $1.25 \times 10^{-11}$ & GO:0034660 \\
& translation & $3.78 \times 10^{-9}$ & GO:0006412 \\
& protein targeting to ER & $1.57 \times 10^{-8}$ & GO:0045047 \\
Liver & response to endoplasmic reticulum stress & $1.40 \times 10^{-6}$ & GO:0034976 \\
& ciliary basal body docking & $2.62 \times 10^{-3}$ & GO:0097711 \\
& nuclear-transcribed mRNA catabolic process & $8.56 \times 10^{-17}$ & GO:0000956 \\
& ER-nucleus signaling pathway & $5.88 \times 10^{-6}$ & GO:0006984 \\
& mitochondrial transmembrane transport & $1.39 \times 10^{-5}$ & GO:1990542 \\
& apoptotic mitochondrial changes & $4.65 \times 10^{-5}$ & GO:0008637 \\
'de novo' protein folding & $1.37 \times 10^{-3}$ & GO:0006458 \\
\hline
\end{tabular}

\subsection{ESR1 Localizes Near Genes Involved in Drug Metabolism}

Previously, we demonstrated that ESR1 functions as a key regulator of several cytochrome P450 genes (CYPs), namely CYP3A4, CYP3A5, CYP3A7, CYP3A43, CYP2C9, CYP2C19, and CYP2A6 [18]. In support of this, we found ESR1 peaks within $50 \mathrm{~kb}$ of the TSS for all of them, except for CYP2C19 (Supplemental Table S3). To further investigate the role of ESR1 in drug metabolism, we generated a list of 170 pharmacogenes, including drug metabolizing enzymes, membrane transporters, liver-enriched TFs, and enzymes related to estrogen metabolism. We searched for ESR1 peaks within $50 \mathrm{~kb}$ of the TSS of these genes and identified ESR1 binding sites located near genes for 39/44 phase I and $37 / 55$ phase II drug metabolism enzymes, 8/11 membrane transporters, 13/14 estrogen metabolism-related enzymes, and 40/46 TFs with known regulatory roles in the liver (Supplemental Table S3). These results further expand the role of ESR1 in regulating drug metabolism and liver gene expression.

\section{Discussion}

Our results found extensive ligand-free and ligand-mediated ESR1 binding in liver cells. By characterizing the localization of ESR1 in response to estrogen treatment, we further categorized ligand-dependent ESR1 binding sites as either gained or lost after treatment. These estrogen-responsive sites primarily occurred within enhancers, with gained locations indicating direct interaction of ESR1 with the ERE and lost sites instead suggesting indirect cofactor recruitment of ESR1 to chromatin. We also identified ESR1 binding sites that were maintained both before and after treatment, which we label here as ligand-independent binding sites. These ligand-independent sites suggest stable cofactor recruitment of ESR1 at gene promoters regardless of ligand availability. Both liganddependent and ligand-independent ESR1 binding sites were identified near genes involved in drug metabolism and transport, estrogen biosynthesis, and key TFs in the liver, consistent with our previous results showing ligand-free ESR1 as a master regulator for the expression of many CYPs [18], supporting the notion that ESR1 may play important roles in drug metabolism in the presence and absence of estrogen. 


\subsection{ERE, Ligand-Free, or Ligand-Independent ESR1 Chromatin Binding}

Genome-wide ligand-free ESR1 localization in MCF-7 cells has been well described in two publications $[16,17]$. Caizzi et al. reported enrichment of both full and half-length ERE's in ligand-free peaks, along with several other cofactors, such as FOXA1 and AP2 $\gamma$. Bojcsuk and Bálint showed that a large subset of ESR1 sites ( $>65 \%$ of all identified ESR1 peaks) are bound by ligand-free ESR1, lack the ERE, and are instead enriched with co-factor motifs. In hepatocytes, we also found that ESR1 primarily associates with chromatin in a ligand-free fashion, with $77 \%$ of the peaks described in the differential binding comparison occurring in the lost and ligand-independent categories (Figure 1B). However, we should draw attention to the greater number of peaks identified in the untreated versus treated hepatocytes (Figure 1A), which may reflect genuine differential ESR1 chromatin enrichment in the two conditions or could potentially be driven by differences in ChIP-Seq sample processing. In support of differential ESR1 enrichment in the two samples, Caizzi et al. also observed 30\% fewer ESR1 peaks after E2 treatment in MCF-7 cells [16]. Also, replicate experiments would likely have improved our ability to determine the cause of the different overall ESR1 peak numbers, but primary hepatocytes are a limited resource, and we chose to pool the samples to limit the effect of individual donor biases. Analysis of the ligand-free peaks showed that the ligand-independent peaks did not contain either a full or half-length ERE, lost sites only showed low enrichment of the half-ERE (data not shown), and the full-length ERE was only detected after treatment (Figure 3). Finally, the liver sample more closely resembled the ligand-independent peaks in localization (Figure 2), motifenrichment (Figure 3), and functional annotation (Table 1). Taken together, our results indicate that indirect localization of ESR1 to the liver genome is fundamental for regulation of gene expression, consistent with the results reported by Bojcsuk and Bálint [17].

\subsection{ESR1 Mediated Gene Regulation in the Liver Occurs through Cofactors and Direct-DNA Binding}

ESR1 binding post-treatment to the ERE has well-characterized roles in gene activation or repression [37]. Also, indirect binding of ESR1 to DNA is integral for its regulation of gene expression, with pioneer factors (e.g., FOXA1, AP2 $\gamma$ ) playing a key role in ESR1 binding to chromatin [38]. Similar to its dual role in regulating genes when directly bound to the ERE, ESR1-containing complexes have been shown to differentially regulate genes lacking an ERE. For instance, SP-1 can bridge ESR1 to DNA in the absence of estrogen, and estrogen treatment leads to co-activator recruitment and gene activation [39-41]. Conversely, a complex containing ligand-free ESR1 at the promoter of the tumor necrosis factor alpha $(T N F \alpha)$ which activates transcription and treatment instead leads to its repression [14]. Because ESR1 regulation is context specific, further studies to dissect the regulatory roles of ESR1 in the liver are warranted.

Regardless of the specific effects on transcription, our results showing co-enrichment of several TFs with ESR1 indicate indirect binding of ESR1 throughout the liver genome. In further support of this, interaction with ESR1 has been shown for many of the coenriched TFs identified in this study: RXRA, HNF4A, CEBPB, SP1 and SP2, subunits of the AP-1 complex (JUN, JUND, and MAZ), GABPA, and the NFY complex [41-49]. Some of these (RXRA, HNF4A, and CEBPB) are known to regulate the expression of pharmacogenes, consistent with our results showing ESR1 localization near their promoters (Supplemental Table S3).

Of note, ligand-independent ESR1 binding sites were highly enriched for the ZNF143 motif in liver and other reproductive tissues and our ChIP-qPCR experiments validated significant colocalization of ZNF143 at three E2-independent sites. ZNF143 has known roles in chromatin looping [50] and it appears to play an essential role in ESR1-mediated gene regulation in MCF-7 cells [51], suggesting that ZNF143 and ESR1 may establish threedimensional chromatin landscapes connecting distal enhancers and promoters to regulate gene expression. Furthermore, ZNF143 was among several other ligand-independent cofactors enriched in cancer cell lines derived from ovarian and uterus tissues (Figure 5). 
Interestingly, in an ESR1 ChIP-Seq experiment conducted in mouse liver tissue, the Staf motif (a component of the ZNF143 motif) was enriched in placebo-treated but not E2treated mouse livers [52]. However, our analyses of the mouse liver data did not identify the ZNF143 or GFY-Staf motifs in the E2-independent dataset, and instead identified low enrichment of ZNF143 in the mouse ESR1 gained category (data not shown). Whether colocalization of ZNF143 and ESR1 is conserved in mammals will require further experimentation. Thus, our results suggest general roles of ESR1 in establishing or stabilizing enhancer-promoter interactions, potentially playing an important role in regulating gene expression. Experiments describing the interaction between ESR1 and ZNF143 and their potential regulation of gene expression through chromatin looping are an intriguing future direction.

\subsection{Implications for ESR1 Regulation in the Liver}

ESR1 is known to be a key transcriptional regulator in the liver [6]. In mouse livers, ESR1 was found to bind fewer sites compared to what had previously been observed in human cells [52]. Our experiments found that in human livers, the number of ESR1 binding sites has greater similarity to that observed in MCF-7 cells [16] and is comparable to other cell lines analyzed in this study (Supplemental Table S2). These binding sites were associated with known liver pathways, such as lipid and insulin metabolism, and more general pathways, such as RNA and protein metabolism (Table 1). In contrast, in mouse livers, ESR1 peaks were predominately associated with liver-specific pathways [52]. Overall, our results suggest an expanded role for ESR1 regulation in human livers and may help explain some of the observed differences in gene expression between humans and mice. For instance, there are several species-specific sex-driven differences in expression of the CYP enzymes $[12,13,53,54]$ and studies have illustrated that human and mouse liver gene expression profiles are highly different, more so than when compared to other tissues in the same species [55,56].

We also identified peaks near important pharmacogenes, genes with roles in estrogen metabolism, and key liver TFs (Supplemental Table S3). Therefore, genetic, epigenetic, and non-genetic (e.g., tamoxifen or fulvestrant, ESR1 targeting drugs) factors that affect ESR1 function and/or expression may contribute significantly to the liver transcriptome, drug metabolism, and liver diseases. Interestingly, ESR1 splice isoforms lacking the Nterminal domain $(\mathrm{ER} \alpha 46)$ are predominant in the liver [57] and several ESR1 isoforms containing truncated C-terminal domains with known altered transactivation and DNAbinding profiles [58,59] are also found in the liver [57]. Moreover, expression of these ESR1 isoforms in the liver is highly variable between individuals [57]. In this study, liver samples were pooled from three males and three females to limit the effect of individual samples on ESR1 localization. Future experiments documenting differences between ESR1 localization in males and females may further our knowledge of the role of ESR1 in driving sexual-dimorphism in the liver. Therefore, the potential alteration of ESR1's regulatory function due to splicing variants may contribute to the well-documented differences in drug response and disease susceptibility between individuals.

\section{Conclusions}

Our ESR1 ChIP-Seq results show discrete genomic binding sites for ligand-free and ligand-bound ESR1 that contain distinct binding motifs and biological pathways in human liver cells, supporting both estrogen-dependent and independent regulatory roles of ESR1. Moreover, we found frequent genomic localization of ESR1 near many pharmacogenes, suggesting the potential broad influence of ESR1 on drug metabolism and drug therapy.

\section{Methods}

\subsection{Liver Tissues and Hepatocyte Samples}

The demographic information for the six liver tissues (three males and three female, age 44 to 73) is provided in Supplemental Table S1. Liver tissues from the six donors 
were pooled and used for ChIP-Seq. Cryopreserved human primary hepatocytes from two donors (both European American, one male and one female, age 32 and 62, respectively) were obtained from Lonza (Basel, Switzerland).

\subsection{Cell Culture and Treatment}

Cryopreserved human hepatocytes were recovered and cultured according to the protocol provided by Lonza. Briefly, cells were thawed and washed once with thawing medium (MCHT50, Lonza, Basel, Switzerland). Then the cells were resuspended in plating medium (MP100, Lonza, Basel, Switzerland), counted, and plated in 6-well collagen coated plates. The cells were cultured in a $37^{\circ} \mathrm{C} / 5 \% \mathrm{CO} 2$ incubator. Four hours later, plating medium was replaced with maintenance medium, containing William's E media supplemented with penicillin/streptomycin/fungizone (100 U/100 $\mu \mathrm{g} / 0.25 \mu \mathrm{g}$ per $\mathrm{mL}$ ), $100 \mathrm{nM}$ dexamethasone, $2 \mathrm{mM}$ L-glutamine, $15 \mathrm{mM}$ HEPES, and ITS $(0.55 \mathrm{mg} / \mathrm{mL}$ human transferrin, $1 \mathrm{mg} / \mathrm{mL}$ bovine insulin and $0.5 \mu \mathrm{g} / \mathrm{mL}$ sodium selenite, from Sigma Aldrich, St. Louis, MO, USA). Eighteen hours after in culture, cells were treated with DMSO or 17-beta-estradiol (E2, $1 \mu \mathrm{M})$ for $8 \mathrm{~h}$, this relatively high dosage was chosen because a previous report demonstrated that E2 is rapidly metabolized in hepatocytes and that they require a higher dosage than other cell lines [20]. The cells were then cross-linked for $15 \mathrm{~min}$ with $1 \%$ formaldehyde. Cells from the two donors were pooled and used for ChIP-Seq.

\subsection{Chromatin Immunoprecipitation Followed by High Throughput Sequencing (ChIP-Seq)}

ChIP-Seq experiments on fixed hepatocytes and frozen liver tissues were performed using a commercial service (Active Motif, Carlsbad, CA, USA), which includes preparation of chromatin from fixed cells and liver tissues, sonication, ChIP with an anti-ESR1 antibody, ChIP-Seq library preparation, next-generation sequencing, and delivery of fastq sequencing data. The anti-ESR1 antibody (sc-543) was obtained from Santa Cruz biotechnology (Santa Cruz Biotech, Dallas, TX, USA).

\subsection{Data Analysis}

All datasets were processed using the same pipeline. Raw fastq files were analyzed with FastQC (v0.11.7) [60] and Trimmomatic (v0.39) [61] was used to remove adaptors, bps with a quality score less than 20, and sequences less than $20 \mathrm{bp}$ in length [61]. Resulting fastq files were aligned to the hg38 genome [62] using Bowtie2 (v2.3.5.1) [63] with the local alignment mode, which allows the reads to be trimmed from both ends to maximize the alignment score. Aligned files were then processed using the factor mode of Homer v4.10 [64] to identify peaks, conduct motif enrichment analyses, and to produce bigwig files. Untreated and E2-treated peaks were generated by comparison to input genomic DNA derived from hepatocytes (Hep input). The liver peaks were determined by comparison to input genomic DNA from liver (Liver input). Shared peaks were defined as any peaks that had an overlap of at least one bp.

Homer v4.10 [64] was also used to determine differential ESR1 peaks. Differential peaks are those that are at least four-fold different between samples (default Homer settings). Gained peaks were determined by calling peaks on the E2-treated sample with the untreated sample as background. Any peaks that were not found in the E2-treated peak analysis were removed (i.e., not found in E2-treated vs. Hep input). Lost peaks were determined by calling peaks on the untreated sample with the E2-treated sample as background and any peaks that were not found in the untreated peak analysis were removed. In both cases, removal of these peaks was to ensure no false background peaks were included in the analysis. Peaks that were found in both untreated and E2-treated samples (within a range of four-fold) were considered E2-independent.

ChromHMM (v1.19) [23] and UCSC genome annotations (GRCh38.p13) [65] were used for annotating the ChIP-Seq peaks. ChromHMM was trained with data from human liver samples (H3K36me3, H3K27ac, H3K4me1, H3K4me3, H3K27me3, H3K9me3) obtained from the human reference epigenome project [66]. The R packages univer- 
salmotif (v1.4.9) [36] and ggseqlogo (v0.1) [67] were used to conduct motif comparisons and generate matrix images. ChIP-Seq density plots were generated from the bigwig files using deepTools2 (v3.1.1) [68]. GREAT (v4.0.4) [69] was used to generate GO terms for the top 5000 peaks in each dataset and REVIGO (http:/ / revigo.irb.hr/) [70] was used to condense redundant GO terms. Datasets used in this study are listed in Supplemental Table S4.

\subsection{Chromatin Immunoprecipitation Followed by $q P C R$ (ChIP-qPCR)}

ChIP was performed in primary human hepatocytes using the ChIP-IT ${ }^{\circledR}$ Express Enzymatic kit (Active Motif, Carlsbad, CA, USA) with an anti-ESR1 (sc-8002x, Santa Cruz Biotech, Dallas, TX, USA) or anti-ZNF143 (sc-100983, Santa Cruz Biotech, Dallas, TX, USA) antibody as described [71]. ESR1 or ZNF143 enriched fragments were measured with real-time PCR using SYBR Green and specific primers (chr3-FP\&RP: CTAGCTGCGCGTAGAGCAC, CATAGTTCAGCCAGCGCGTC; chr7-FP\&RP: CCTGGAGGGAGACATAGCG, CCGGAAGCGGCTAAGACAC; chr12-FP\&RP: GGACTTGTAGTCTCCCACGC, GGACGGTAGTCACACGACAG) and fold enrichment was calculated relative to a negative control prepared with nonspecific IgG antibody. Genomic information for the ChIP-qPCR targets is described in Supplemental Table S5).

Supplementary Materials: The following are available online at https:/ /www.mdpi.com/1422-0 067/22/3/1461/s1. Table S1. Sample demographic information. Table S2. ESR1 ChIP-Seq peaks identified in all experiments. Table S3. ESR1 ChIP-Seq peaks located within $50 \mathrm{~kb}$ of selected liver genes. Table S4. Datasets used in this study. Table S5. ChIP-qPCR peak information. Figure S1. ChIPSeq peak examples. The three different panels are selected to show ChIP-Seq peaks used to categorize ESR1 binding into lost, gained, and E2-independent datasets. Asterisks indicate peaks that are E2-independent and are found in both untreated and E2-treated samples. Solid-filled circles indicate peaks that are either gained (located in E2-treated only) or lost (located in untreated only). Figure S2. Transcription factor colocalization across all ESR1 binding categories. Heatmaps illustrating ChIP-Seq read density centered on ESR1 peaks within a $\pm 5 \mathrm{~kb}$ window. The figure is organized into four rows separated into four blocks. Each row shows TF density around a specific ESR1 binding category (gained, lost, E2- independent, and liver). Each vertical line separates TFs in blocks that were enriched in each specific ESR1 category. Plots highlighted with a dark border were identified in both experiments (e.g., RXRA was identified in both gained and liver). TF ChIP-Seq data were obtained from published datasets conducted in HepG2 cells. Darker intensity indicates higher enrichment, as indicated by the legends to the right of the plots.

Author Contributions: J.M.C. analyzed the data and wrote the manuscript. Z.H. analyzed the data. D.W. designed the experiments and helped to write the manuscript. All authors have read and agreed to the published version of the manuscript.

Funding: This work was supported by National Institute of Health (R01 GM120396 to D.W.). The content is solely the responsibility of the authors and does not necessarily represent the official views of the National Institutes of Health.

Institutional Review Board Statement: The study was conducted according to the guidelines of the Declaration of Helsinki and approved by The University of Florida Biosafety Committee and IRB Committee approved the primary cell culture and human tissue studies, respectively (non-human, UF IRB201801313).

Informed Consent Statement: Consent to participate was not applicable, as deidentified tissue samples and cells we used in this study.

Data Availability Statement: The data has been deposited in the gene expression omnibus under GSE158856.

Acknowledgments: Liver samples were provided by the Cooperative Human Tissue Network, which is funded by the National Cancer Institute.

Conflicts of Interest: The authors declare that they have no competing interests. 


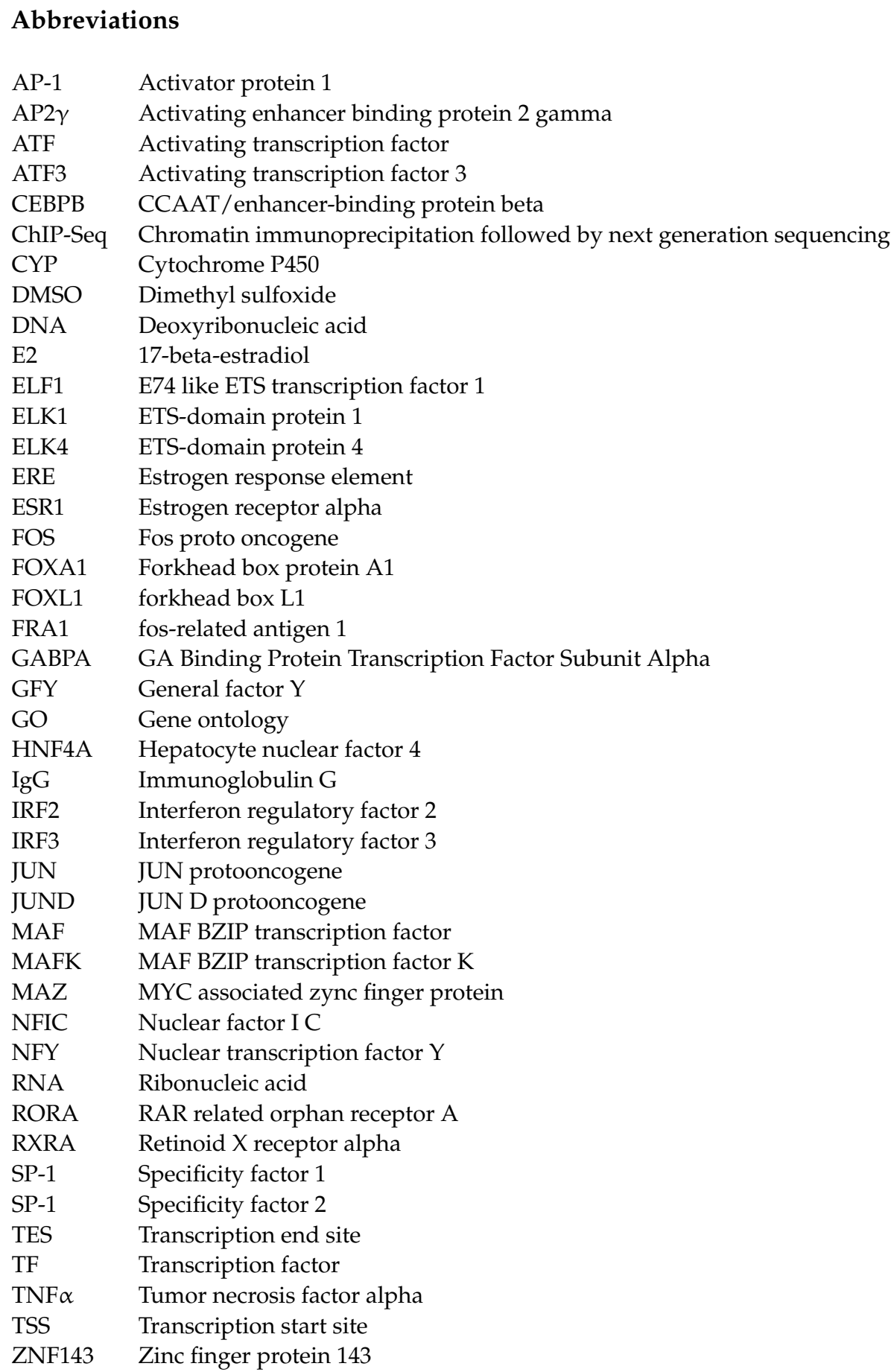

\section{References}

1. Heldring, N.; Pike, A.; Andersson, S.; Matthews, J.; Cheng, G.; Hartman, J.; Tujague, M.; Ström, A.; Treuter, E.; Warner, M.; et al. Estrogen Receptors: How Do They Signal and What Are Their Targets. Physiol. Rev. 2007, 87, 905-931. [CrossRef] [PubMed]

2. Gruber, C.J.; Tschugguel, W.; Schneeberger, C.; Huber, J.C. Production and Actions of Estrogens. N. Engl. J. Med. 2002, 346, 340-352. [CrossRef] [PubMed]

3. Ascenzi, P.; Bocedi, A.; Marino, M. Structure-function relationship of estrogen receptor alpha and beta: Impact on human health. Mol. Aspects. Med. 2006, 27, 299-402. [CrossRef] [PubMed]

4. Murphy, C.G.; Dickler, M.N. Endocrine resistance in hormone-responsive breast cancer: Mechanisms and therapeutic strate-gies. Endocr. Relat. Cancer 2016, 23, R337-R352. [CrossRef] [PubMed]

5. Qiu, S.; Vazquez, J.T.; Boulger, E.; Liu, H.; Xue, P.; Hussain, M.A.; Wolfe, A. Hepatic estrogen receptor $\alpha$ is critical for regulation of gluconeogenesis and lipid metabolism in males. Sci. Rep. 2017, 7, 1-12. [CrossRef] 
6. Palmisano, B.T.; Zhu, L.; Stafford, J. Role of Estrogens in the Regulation of Liver Lipid Metabolism. Adv. Exp. Med. Biol. 2017, 1043, 227-256. [CrossRef]

7. Iyer, J.K.; Kalra, M.; Kaul, A.; Payton, M.E.; Kaul, R. Estrogen receptor expression in chronic hepatitis C and hepatocellular carci-noma pathogenesis. World J. Gastroenterol. 2017, 23, 6802-6816. [CrossRef]

8. Li, Z.; Tuteja, G.; Schug, J.; Kaestner, K.H. Foxa1 and Foxa2 Are Essential for Sexual Dimorphism in Liver Cancer. Cell 2012, 148, 72-83. [CrossRef]

9. Flouriot, G.; Griffin, C.; Kenealy, M.; Sonntag-Buck, V.; Gannon, F. Differentially expressed messenger RNA isoforms of the hu-man estrogen receptor-alpha gene are generated by alternative splicing and promoter usage. Mol. Endocrinol. 1998, 12, 1939-1954.

10. Hassan, M.M.; Botrus, G.; Abdel-Wahab, R.; Wolff, R.A.; Li, D.; Tweardy, D.; Phan, A.T.; Hawk, E.; Javle, M.; Lee, J.S.; et al. Estrogen Re-placement Reduces Risk and Increases Survival Times of Women with Hepatocellular Carcinoma. Clin. Gastroenterol. Hepatol. 2017, 15, 1791-1799. [CrossRef]

11. Lonardo, A.; Nascimbeni, F.; Ballestri, S.; Fairweather, D.; Win, S.; Than, T.A.; Abdelmalek, M.F.; Suzuki, A. Sex Differences in Non-alcoholic Fatty Liver Disease: State of the Art and Identification of Research Gaps. Hepatology 2019, 70, 1457-1469. [CrossRef] [PubMed]

12. Zhang, Y.; Klein, K.; Sugathan, A.; Nassery, N.; Dombkowski, A.; Zanger, U.M.; Waxman, D.J. Transcriptional Profiling of Human Liver Identifies Sex-Biased Genes Associated with Polygenic Dyslipidemia and Coronary Artery Disease. PLoS ONE 2011, 6, e23506. [CrossRef] [PubMed]

13. Wolbold, R.; Klein, K.; Burk, O.; Nüssler, A.K.; Neuhaus, P.; Eichelbaum, M.; Schwab, M.; Zanger, U.M. Sex is a major determinant of CYP3A4 expression in human liver. Hepatology 2003, 38, 978-988. [CrossRef] [PubMed]

14. Cvoro, A.; Tzagarakis-Foster, C.; Tatomer, D.; Paruthiyil, S.; Fox, M.S.; Leitman, D.C. Distinct Roles of Unliganded and Liganded Estrogen Receptors in Transcriptional Repression. Mol. Cell 2006, 21, 555-564. [CrossRef] [PubMed]

15. Cardamone, M.D.; Bardella, C.; Gutierrez, A.; Di Croce, L.; Rosenfeld, M.G.; Di Renzo, M.F.; De Bortoli, M. ERalpha as lig-andindependent activator of $\mathrm{CDH}-1$ regulates determination and maintenance of epithelial morphology in breast cancer cells. Proc. Natl. Acad. Sci. USA 2009, 106, 7420-7425. [CrossRef] [PubMed]

16. Caizzi, L.; Ferrero, G.; Cutrupi, S.; Cordero, F.; Ballaré, C.; Miano, V.; Reineri, S.; Ricci, L.; Friard, O.; Testori, A.; et al. Genome-wide activity of unliganded estrogen receptor- $\alpha$ in breast cancer cells. Proc. Natl. Acad. Sci. USA 2014, 111, 4892-4897. [CrossRef]

17. Bojcsuk, D.; Balint, B.L. Classification of different types of estrogen receptor alpha binding sites in MCF-7 cells. J. Biotechnol. 2019, 299, 13-20. [CrossRef]

18. Wang, D.; Lu, R.; Rempala, G.; Sadee, W. Ligand-Free Estrogen Receptor $\alpha$ (ESR1) as Master Regulator for the Expression of CYP3A4 and Other Cytochrome P450 Enzymes in the Human Liver. Mol. Pharmacol. 2019, 96, 430-440. [CrossRef]

19. Danielson, P.B. The Cytochrome P450 Superfamily: Biochemistry, Evolution and Drug Metabolism in Humans. Curr. Drug Metab. 2002, 3, 561-597. [CrossRef]

20. Choi, S.-Y.; Koh, K.H.; Jeong, H. Isoform-Specific Regulation of Cytochromes P450 Expression by Estradiol and Progesterone. Drug Metab. Dispos. 2013, 41, 263-269. [CrossRef]

21. Go, R.-E.; Hwang, K.-A.; Choi, K. Cytochrome P450 1 family and cancers. J. Steroid Biochem. Mol. Biol. 2015, 147, 24-30. [CrossRef] [PubMed]

22. Kent, W.J.; Sugnet, C.W.; Furey, T.S.; Roskin, K.M.; Pringle, T.H.; Zahler, A.M.; Haussler, A.D. The Human Genome Browser at UCSC. Genome Res. 2002, 12, 996-1006. [CrossRef] [PubMed]

23. Ernst, J.; Kellis, M. ChromHMM: Automating chromatin-state discovery and characterization. Nat. Methods 2012, 9, 215-216. [CrossRef] [PubMed]

24. Gertz, J.; Savic, D.; Varley, K.E.; Partridge, E.C.; Safi, A.; Jain, P.; Cooper, G.M.; Reddy, T.E.; Crawford, G.E.; Myers, R.M. Distinct proper-ties of cell-type-specific and shared transcription factor binding sites. Mol. Cell 2013, 52, 25-36. [CrossRef] [PubMed]

25. Consortium, E.P. An integrated encyclopedia of DNA elements in the human genome. Nature 2012, 489, 57-74. [CrossRef] [PubMed]

26. Bejjani, F.; Evanno, E.; Zibara, K.; Piechaczyk, M.; Jariel-Encontre, I. The AP-1 transcriptional complex: Local switch or remote command? Biochim. Biophys. Acta (BBA) Bioenerg. 2019, 1872, 11-23. [CrossRef]

27. Zhao, G.-N.; Jiang, D.-S.; Li, H.-L. Interferon regulatory factors: At the crossroads of immunity, metabolism, and disease. Biochim. Biophys. Acta (BBA) Mol. Basis Dis. 2015, 1852, 365-378. [CrossRef]

28. Zhang, X.J.; Jiang, D.S.; Li, H. The interferon regulatory factors as novel potential targets in the treatment of cardiovascular dis-eases. Br. J. Pharmacol. 2015, 172, 5457-5476. [CrossRef]

29. Benner, C.; Konovalov, S.; Mackintosh, C.; Hutt, K.R.; Stunnenberg, R.; Garcia-Bassets, I. Decoding a Signature-Based Model of Transcription Cofactor Recruitment Dictated by Cardinal Cis-Regulatory Elements in Proximal Promoter Regions. PLoS Genet. 2013, 9, e1003906. [CrossRef]

30. Suske, G. The Sp-family of transcription factors. Gene 1999, 238, 291-300. [CrossRef]

31. Vahrenkamp, J.M.; Yang, C.H.; Rodriguez, A.C.; Almomen, A.; Berrett, K.C.; Trujillo, A.N.; Guillen, K.P.; Welm, B.E.; Jarboe, E.A.; Janat-Amsbury, M.M.; et al. Clinical and Genomic Crosstalk between Glucocorticoid Receptor and Estrogen Receptor $\alpha$ In En-dometrial Cancer. Cell Rep. 2018, 22, 2995-3005. [CrossRef] [PubMed] 
32. Chakravarty, D.; Sboner, A.; Nair, S.S.; Giannopoulou, E.G.; Li, R.; Hennig, S.; Mosquera, J.M.; Pauwels, J.; Park, K.; Kossai, M.; et al. The oestrogen receptor alpha-regulated lncRNA NEAT1 is a critical modulator of prostate cancer. Nat. Commun. 2014, 5, 1-6. [CrossRef] [PubMed]

33. Watters, R.J.; Hartmaier, R.J.; Osmanbeyoglu, H.U.; Gillihan, R.M.; Rae, J.M.; Liao, L.; Chen, K.; Li, W.; Lu, X.; Oesterreich, S. Steroid re-ceptor coactivator-1 can regulate osteoblastogenesis independently of estrogen. Mol. Cell Endocrinol. 2017, 448, 21-27. [CrossRef] [PubMed]

34. Hao, D.; Li, J.; Wang, J.; Meng, Y.; Zhao, Z.; Zhang, C.; Miao, K.; Deng, C.; Tsang, B.K.; Wang, L.; et al. Non-classical estrogen signaling in ovarian cancer improves chemo-sensitivity and patients outcome. Theranostics 2019, 9, 3952-3965. [CrossRef] [PubMed]

35. Schmidt, D.; Schwalie, P.C.; Ross-Innes, C.S.; Hurtado, A.; Brown, G.D.; Carroll, J.S.; Flicek, P.; Odom, D.T. A CTCF-independent role for cohesin in tissue-specific transcription. Genome Res. 2010, 20, 578-588. [CrossRef] [PubMed]

36. Tremblay, B. Universalmotif: Import, Modify, and Export Motifs with R. In R package Version 1.4.9. R Package Version 1.4.9. 2020. Available online: https://github.com/bjmt/universalmotif (accessed on 17 March 2020).

37. Welboren, W.J.; van Driel, M.A.; Janssen-Megens, E.M.; van Heeringen, S.J.; Sweep, F.C.; Span, P.N.; Stunnenberg, H.G. ChIP-Seq of ERalpha and RNA polymerase II defines genes differentially responding to ligands. EMBO J. 2009, 28, 418-1428. [CrossRef] [PubMed]

38. Magnani, L.; Lupien, M. Chromatin and epigenetic determinants of estrogen receptor alpha (ESR1) signaling. Mol. Cell. Endocrinol. 2014, 382, 633-641. [CrossRef]

39. Safe, S.; Kim, K. Non-classical genomic estrogen receptor (ER)/specificity protein and ER/activating protein-1 signaling pathways. J. Mol. Endocrinol. 2008, 41, 263-275. [CrossRef]

40. Dong, J.; Tsai-Morris, C.H.; Dufau, M.L. A novel estradiol/estrogen receptor alpha-dependent transcriptional mechanism con-trols expression of the human prolactin receptor. J. Biol. Chem. 2006, 281, 18825-18836. [CrossRef]

41. Koslowski, M.; Türeci, Ö.; Huber, C.; Sahin, U. Selective activation of tumor growth-promoting Ca2+ channel MS4A12 in colon cancer by caudal type homeobox transcription factor CDX2. Mol. Cancer 2009, 8, 1-6. [CrossRef]

42. Lee, S.K.; Choi, H.S.; Song, M.R.; Lee, M.O.; Lee, J.W. Estrogen receptor, a common interaction partner for a subset of nuclear recep-tors. Mol. Endocrinol. 1998, 12, 1184-1192. [CrossRef] [PubMed]

43. Boruk, M.; Savory, J.G.; Haché, R.J. AF-2-dependent potentiation of CCAAT enhancer binding protein beta-mediated transcriptional activation by glucocorticoid receptor. Mol. Endocrinol. 1998, 12, 1749-1763. [PubMed]

44. He, S.; Sun, J.-M.; Li, L.; Davie, J.R. Differential Intranuclear Organization of Transcription Factors Sp1 and Sp3. Mol. Biol. Cell 2005, 16, 4073-4083. [CrossRef] [PubMed]

45. Teyssier, C.; Belguise, K.; Galtier, F.; Chalbos, D. Characterization of the Physical Interaction between Estrogen Receptor $\alpha$ and JUN Proteins. J. Biol. Chem. 2001, 276, 36361-36369. [CrossRef]

46. Björnström, L.; Sjöberg, M. Mechanisms of Estrogen Receptor Signaling: Convergence of Genomic and Nongenomic Actions on Target Genes. Mol. Endocrinol. 2005, 19, 833-842. [CrossRef]

47. Campbell, T.M.; Castro, M.A.A.; De Oliveira, K.G.; Ponder, B.A.J.; Meyer, K.B. ER $\alpha$ Binding by Transcription Factors NFIB and YBX1 Enables FGFR2 Signaling to Modulate Estrogen Responsiveness in Breast Cancer. Cancer Res. 2018, 78, 410-421. [CrossRef]

48. Ly, L.L.; Yoshida, H.; Yamaguchi, M. Nuclear transcription factor $Y$ and its roles in cellular processes related to human disease. Am. J. Cancer Res. 2013, 3, 339-346.

49. Nassa, G.; Giurato, G.; Salvati, A.; Gigantino, V.; Pecoraro, G.; Lamberti, J.; Rizzo, F.; Nyman, T.A.; Tarallo, R.; Weisz, A. The RNA-mediated estrogen receptor $\alpha$ interactome of hormone-dependent human breast cancer cell nuclei. Sci. Data 2019, 6, 1-8. [CrossRef]

50. Wen, Z.; Huang, Z.-T.; Zhang, R.; Peng, C. ZNF143 is a regulator of chromatin loop. Cell Biol. Toxicol. 2018, 34, 471-478. [CrossRef]

51. Treloar, A. The Chromatin-Looping Factor ZNF143 is Genetically Altered and Promotes the Oestrogen Response in Breast Cancer. Ph.D. Thesis, University of Toronto, Toronto, ON, Canada, 2016.

52. Palierne, G.; Fabre, A.; Solinhac, R.; Le Péron, C.; Avner, S.; Lenfant, F.; Fontaine, C.; Salbert, G.; Flouriot, G.; Arnal, J.-F.; et al. Changes in Gene Expression and Estrogen Receptor Cistrome in Mouse Liver Upon Acute E2 Treatment. Mol. Endocrinol. 2016, 30, 709-732. [CrossRef]

53. Sakuma, T.; Takai, M.; Endo, Y.; Kuroiwa, M.; Ohara, A.; Jarukamjorn, K.; Honma, R.; Nemoto, N. A Novel Female-Specific Member of the CYP3A Gene Subfamily in the Mouse Liver. Arch. Biochem. Biophys. 2000, 377, 153-162. [CrossRef] [PubMed]

54. Sakuma, T.; Endo, Y.; Mashino, M.; Kuroiwa, M.; Ohara, A.; Jarukamjorn, K.; Nemoto, N. Regulation of the expression of two fe-male-predominant CYP3A mRNAs (CYP3A41 and CYP3A44) in mouse liver by sex and growth hormones. Arch. Biochem. Biophys. 2002, 404, 234-242. [CrossRef]

55. Lin, S.; Lin, Y.; Nery, J.R.; Urich, M.A.; Breschi, A.; Davis, C.A.; Dobin, A.; Zaleski, C.; Beer, M.A.; Chapman, W.C.; et al. Comparison of the transcriptional landscapes between human and mouse tissues. Proc. Natl. Acad. Sci. USA 2014, 111, 17224-17229. [CrossRef] [PubMed]

56. Yu, Y.; Ping, J.; Chen, H.; Jiao, L.; Zheng, S.; Han, Z.G.; Hao, P.; Huang, J. A comparative analysis of liver transcriptome suggests di-vergent liver function among human, mouse and rat. Genomics 2010, 96, 281-289. [CrossRef] [PubMed] 
57. Sun, J.; Collins, J.; Ling, D.; Wang, D. Highly Variable Expression of ESR1 Splice Variants in Human Liver: Implication in the Liver Gene Expression Regulation and Inter-Person Variability in Drug Metabolism and Liver Related Diseases. J. Mol. Genet. Med. 2019, 13, 434. [PubMed]

58. Hattori, Y.; Ishii, H.; Munetomo, A.; Watanabe, H.; Morita, A.; Sakuma, Y.; Ozawa, H. Human C-terminally truncated ER $\alpha$ variants resulting from the use of alternative exons in the ligand-binding domain. Mol. Cell. Endocrinol. 2016, 425, 111-122. [CrossRef] [PubMed]

59. Flouriot, G.; Brand, H.; Denger, S.; Metivier, R.; Kos, M.; Reid, G.; Sonntag-Buck, V.; Gannon, F. Identification of a new isoform of the human estrogen receptor-alpha (hER-alpha) that is encoded by distinct transcripts and that is able to repress hER-alpha ac-tivation function 1. EMBO J. 2000, 19, 4688-4700. [CrossRef] [PubMed]

60. Andrews, S. FastQC A Quality Control Tool for High Throughput Sequence Data. Available online: http://www.bioinformatics. babraham.ac.uk/projects/fastqc/ (accessed on 6 December 2019).

61. Bolger, A.M.; Lohse, M.; Usadel, B. Trimmomatic: A flexible trimmer for Illumina sequence data. Bioinformatics 2014, 30, 2114-2120. [CrossRef]

62. Schneider, V.A.; Graves-Lindsay, T.; Howe, K.; Bouk, N.; Chen, H.-C.; Kitts, P.A.; Murphy, T.D.; Pruitt, K.D.; Thibaud-Nissen, F.; Albracht, D.; et al. Evaluation of GRCh38 and de novo haploid genome assemblies demonstrates the enduring quality of the reference assembly. Genome Res. 2017, 27, 849-864. [CrossRef]

63. Langmead, B.; Salzberg, S.L. Fast gapped-read alignment with Bowtie 2. Nat. Methods 2012, 9, 357-359. [CrossRef]

64. Heinz, S.; Benner, C.; Spann, N.; Bertolino, E.; Lin, Y.C.; Laslo, P.; Cheng, J.X.; Murre, C.; Singh, H.; Glass, C.K. Simple Combinations of Lineage-Determining Transcription Factors Prime cis-Regulatory Elements Required for Macrophage and B Cell Identities. Mol. Cell 2010, 38, 576-589. [CrossRef] [PubMed]

65. Haeussler, M.; Zweig, A.S.; Tyner, C.; Speir, M.L.; Rosenbloom, K.R.; Raney, B.J.; Lee, C.M.; Lee, B.T.; Hinrichs, A.S.; Gonzalez, J.N.; et al. The UCSC Genome Browser database: 2019 update. Nucleic Acids Res. 2019, 47, D853-D858. [CrossRef] [PubMed]

66. Kundaje, A.; Jiang, P.; Meuleman, W.; Ernst, J.; Bilenky, M.; Yen, A.; Heravi-Moussavi, A.; Kheradpour, P.; Zhang, Z.; Wang, J.; et al. Integrative analysis of 111 reference human epigenomes. Nat. Cell Biol. 2015, 518, 317-330. [CrossRef] [PubMed]

67. Wagih, O. Ggseqlogo: A versatile R package for drawing sequence logos. Bioinformatics 2017, 33, 3645-3647. [CrossRef]

68. Ramírez, F.; Ryan, D.P.; Grüning, B.; Bhardwaj, V.; Kilpert, F.; Richter, A.S.; Heyne, S.; Dündar, F.; Manke, T. deepTools2: A next gener-ation web server for deep-sequencing data analysis. Nucleic Acids Res. 2016, 44, W160-W165. [CrossRef]

69. McLean, C.Y.; Bristor, D.; Hiller, M.; Clarke, S.L.; Schaar, B.T.; Lowe, C.B.; Wenger, A.M.; Bejerano, G. GREAT improves functional in-terpretation of cis-regulatory regions. Nat. Biotechnol. 2010, 28, 495-501. [CrossRef]

70. Supek, F.; Bošnjak, M.; Škunca, N.; Šmuc, T. REVIGO Summarizes and Visualizes Long Lists of Gene Ontology Terms. PLoS ONE 2011, 6, e21800. [CrossRef]

71. Wang, D.; Papp, A.C.; Sun, X. Functional characterization of CYP2D6 enhancer polymorphisms. Hum. Mol. Genet. 2015, 24, 1556-1562. [CrossRef] 